\title{
Changes in Cognitive Function and in the Levels of Glycosylated Haemoglobin (HbA1c) in Older Women with Type 2 Diabetes Mellitus Subjected to a Cardiorespiratory Exercise Programme
}

\author{
Edgardo Molina-Sotomayor ${ }^{1}\left(\mathbb{D}\right.$, Wanesa Onetti-Onetti ${ }^{2}\left(\mathbb{D}\right.$, Alfonso Castillo-Rodríguez $^{3}(\mathbb{C})$ and \\ Jose Antonio González-Jurado 4,*(D) \\ 1 Departamento de Educación Física, Universidad Metropolitana de Ciencias de la Educación, \\ 7760197 Metropolitana, Chile; edgardo.molina@umce.cl \\ 2 Facultad de Educación, Universidad Internacional de La Rioja, 26006 Logroño, Spain; wanesa.onetti@unir.net \\ 3 Department of Physical Education and Sports, University of Granada, 18011 Granada, Spain; acastillo@ugr.es \\ 4 Physical Performance and Sports Research Centre, University of Pablo de Olavide, 41013 Sevilla, Spain \\ * Correspondence: jagonjur@upo.es; Tel.: +34-954-977-586
}

Received: 12 April 2020; Accepted: 16 June 2020; Published: 19 June 2020

check for updates

\begin{abstract}
Ageing and diabetes are recognised as important risk factors for the development of cognitive deterioration. The aim was to analyse the effects of a walking-based training programme on cognitive deterioration and glycosylated haemoglobin (HbA1c) in older women with type 2 diabetes. This was a six-month experimental and longitudinal study with an experimental group $(E G)(n=57)$ and a control group $(C G)(n=52)$. All participants were diabetic with hypoglycaemic treatment. EG carried out a walking-based training program. After the training, we evaluated the diabetic state $(\mathrm{HbA} 1 \mathrm{c})$, cognitive functioning with the Mini-Mental State Examination (MMSE), cardiorespiratory fitness (VO2max) and body mass index (BMI). Results: EG obtained better results than CG in all the analysed variables. EG showed a significant improvement in the levels of HbA1c $(-4.5 \% ; p<0.001)$, VO2max $(+5.9 \% ; p<0.001)$ and BMI $(-5.4 \% ; p<0.001)$; it also obtained increases in the scores of cognitive functioning, which were statistically significant in all dimensions, except for calculation $(p=0.384)$ and language $(p=0.168)$. Conclusion: The aerobic treatment produced significant improvements in the diabetic state and cognitive functioning in older women with type 2 diabetes.
\end{abstract}

Keywords: physical activity; walking; training; health; cognitive impairment; ageing

\section{Introduction}

Type 2 diabetes mellitus (DM2) represents an important disease burden in terms of morbidity, mortality and disability [1,2], which is associated with states of fragility [3]. More evident states of prefragility-fragility are shown in patients with DM2 than in non-diabetic people of the same age and sex [4], with both states increasing the risk of mortality and cardiovascular events [5]. Therefore, aging and diabetes are recognised as important risk factors for the development of functional deterioration and disability [6]. However, changes in lifestyle, nutrition, physical activity and cognitive training decrease the fragility index [7], since it has been reported that cognitive deterioration and/or physical fragility are powerful factors that identify diabetic people with high mortality risk [8].

DM2 has been shown to increase the risk of cognitive impairment [9] and depression [10]; it has also been proven to reduce pharmacological adherence and increase metabolic decompensation [11]. Likewise, DM2 patients present greater cognitive impairment, with prevalence of psychiatric 
disorders [12]. This cognitive fragility, in addition to physical fragility, is more frequent in younger individuals with DM2 than in those without diabetes [13], with the cognitive decrease being more evident in older women with DM2, who generally have a lower education level [14]. Cognitive decline in older individuals with DM2 has been attributed to a decrease in cerebral blood flow, affecting the medial temporal lobe and lower parietal regions [15], to brain network atrophy [16] and to the action of the adipocytokine protein nicotinamide phosphoribosyltransferase, which favours early cognitive damage [17].

Several studies associate diabetes with cognitive deterioration, since a linear correlation has been found between the latter and the blood levels of $\mathrm{HbA1c}$, regardless of the diabetic state [18], suggesting that people with DM2 can reduce the risk of cognitive deterioration by maintaining good long-term glycaemic control [19]. High HbA1c concentration is associated with greater risk of dementia [20], since the former has been correlated with poorer executive functioning among people with cognitive deterioration [21], thus the presence of high levels of glycosylated peptides can be associated with greater cognitive deterioration, especially affecting the executive functions [22]. Furthermore, it has been concluded in animal models that aerobic exercise could partially reverse the cognitive deterioration associated with diabetes, as it reduces oxidative stress and brain inflammation [23]. Physical activity from early childhood to old age has been reported to have cognitive benefits, with potential long-lasting effects on brain health [24]. It has been asserted that physical training can potentially contribute to improving cognitive performance in patients with DM2 [25]. Moreover, slow walking has been previously identified as a predictor of both cognitive deterioration and dementia [14]. Likewise, the increase in walking speed has shown benefits in the cognitive functioning of older and sedentary people with diabetes [26].

However, it is globally estimated that $27 \%$ of cases of DM2 are caused by physical inactivity [27]. Furthermore, the literature does not provide complete evidence to assert that physical activity or exercise interventions contribute to improving the cognitive functioning of patients with DM2 or glucose intolerance [28]. The studies published to date on this topic do not seem to be sufficient to conduct a complete evaluation of the effects of non-pharmacological interventions to improve the cognition of DM2 patients [29].

The aim of the present study was to analyse the effects of a progressive walking training intervention on plasma concentrations of $\mathrm{HbA} 1 \mathrm{c}$ and cognitive function in older women with type 2 diabetes mellitus and mild cognitive impairment (MCI).

\section{Materials and Methods}

\subsection{Participants}

This was a 6-month, experimental, longitudinal, and non-probabilistic study. Figure 1 shows the flowchart for the sample recruitment from a potential population of older individuals $(n=1150)$, who were registered patients of a healthcare centre of the Metropolitan Region of Santiago de Chile. Older women $(n=232)$ diagnosed with type 2 diabetes mellitus (DM2) were selected, all of whom had been under treatment with Metformin ( $850 \mathrm{mg} /$ day) for 3 or 5 months. All the women were pensioners and they claimed to have a sedentary lifestyle, therefore, they just carried out basic domestic activities for self-help. Of this group of 232 women, 114 participated in the study and 107 completed the entire intervention period.

The sample size was calculated with an $\alpha$ of $5 \%, 95 \%$ confidence interval, and 0.5 minimal detectable difference. Two groups were randomised as experimental group (EG, $\mathrm{n}=55$ ) and control group ( $C G, n=52$ ). Both groups maintained the pharmacological treatment throughout the entire study. EG followed an aerobic physical training regime, which consisted of a structured programme of progressive walking. CG did not carry out any planned physical activity and performed their activities of daily living (ADLs). The women of both groups had an academic level that allowed them to read and write correctly without assistance. Table 1 shows the characteristics of the participants. 


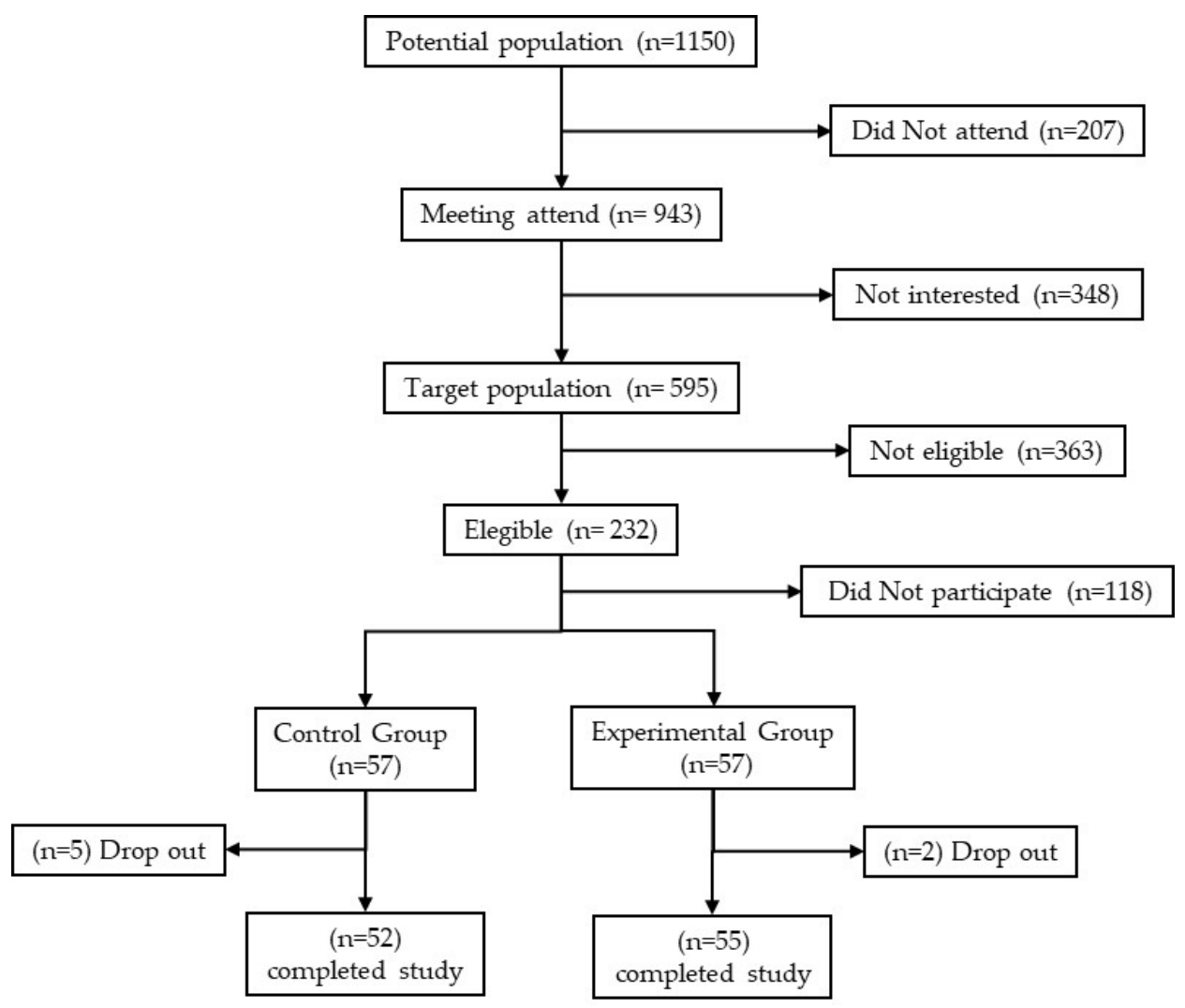

Figure 1. Recruitment flowchart.

Table 1. Participants baseline.

\begin{tabular}{ccccc}
\hline & \multicolumn{2}{c}{ Experimental Group (n = 55) } & \multicolumn{2}{c}{ Control Group (n = 52) } \\
\cline { 2 - 5 } & Mean \pm SD & 95\% (CI) & Mean \pm SD & 95\% (CI) \\
\hline Age (years) & $72.3 \pm 3.7$ & $(71.3$ to 73.3) & $71 \pm 3.3$ & $(70.1$ to 72) \\
Weight (kg) & $60.8 \pm 3.7$ & $(59.7$ to 61.8$)$ & $60.1 \pm 3.5$ & $(59.1$ to 61.1) \\
Height (m) & $1.54 \pm 0.05$ & $(1.52$ to 1.55$)$ & $1.53 \pm 0.04$ & $(1.51$ to 1.54$)$ \\
Primary school completed & \multicolumn{2}{c}{$100 \%$} & \multicolumn{2}{c}{$100 \%$} \\
High school completed & \multicolumn{2}{c}{$92 \%$} & \multicolumn{2}{c}{$89 \%$} \\
\hline
\end{tabular}

The following inclusion criteria were considered: (1) women over 65 years of age registered in the participating healthcare centre and with updated clinical examinations; (2) medical authorization compatible with the requirements of the cardiorespiratory physical training; (3) patients diagnosed with DM2 and under treatment with Metformin ( $850 \mathrm{mg} /$ day) (4); pharmacological treatment of 3-5 months since diagnosis; (5) Mini-Mental State Examination (MMSE) score $\leq 24$ points; (6) serum $\mathrm{HbA} 1 \mathrm{c} \geq$ $7.5 \%$; (7) patients with reading and writing skills; and (8) signed voluntary consent. The following exclusion criteria were applied: (1) suffering from depressive episodes with medication; (2) pathological conditions incompatible with physical exercise; (3) missing over $20 \%$ of the training sessions; (4) showing some severe pathology during the study period. The process followed the indications of the Declaration of Helsinki approved by the World Medical Association [30] and by the Ethical Committee of the Pablo de Olavide University (Seville, Spain).

\subsection{Procedure}

For the blood analysis, the healthcare personnel of the healthcare centre took vein blood samples from the participants in the morning. The puncture was performed in the forearm vein, extracting 
$10 \mathrm{~mL}$ of blood into vacuum collection tubes for conservation and later analysis. The stable fraction of $\mathrm{HbA} 1 \mathrm{c}$ was determined in the laboratory of the healthcare centre by ion exchange chromatography (IEC). The results were recorded for later treatment, assigning them a number associated with the name of each patient.

Cognitive deterioration was evaluated using the Mini-Mental State Examination (MMSE) [31] in its Spanish version, which had been previously validated in a sample of older Chilean adults [32]. We considered the recommendations on the clinical use of the Spanish versions of the MMSE [33] and we used a total valuation of 30 points and a cutoff score of $\leq 24$ for the diagnosis of pathological suspicion of mild cognitive impairment (MCI) [34]. The test was administered individually and with no time limit. Prior to its administration, the test instructions were read, assigning an identification number to each individual with the aim of protecting their identity.

The 6-min walk test (6MWT) allowed determining the cardiorespiratory fitness of the participants (VO2max). This test can accurately estimate VO2max in a healthy adult population [35] with excellent test-retest reliability and moderate construct validity for the evaluation of patients with good functional capacity to perform exercises [36]. It can also be used to predict cardiorespiratory fitness in asymptomatic individuals [37] and it has been used in studies with patients who had different symptoms [38-40]. Moreover, it has been reported that the 6MWT is easy to perform and reliable for the evaluation of cardiorespiratory fitness in patients with DM2 [41]. Likewise, a significant correlation has been observed between the results of this test and the values of $\mathrm{HbA1c}$ [42]; it has even provided reliable and valid results to evaluate the walking capacity in fragile older individuals with dementia [43]. The 6MWT was carried out in homogenous groups of 10 participants in a 400-metre flat track, marked every 50 metres. The participants were encouraged to walk the longest possible distance in $6 \mathrm{~min}$. The test was administered twice at the beginning of the intervention (test-retest), obtaining a correlation coefficient of $\mathrm{r}=0.97$ between the two measurements. VO2max was estimated using equation the following equation [44]:

$$
\begin{gathered}
\mathrm{VO} 2 \mathrm{max}=17.59+0.028(6 \mathrm{MWT}[\mathrm{m}])-0.256\left(\mathrm{BMI}\left[\mathrm{kg} / \mathrm{m}^{-2}\right]\right)-2.567(\text { gender: } 0 \text { male, } 1 \text { female }) \\
\pm 3.25 \mathrm{~mL} / \mathrm{kg}^{-1} \bullet \mathrm{min}^{-1}
\end{gathered}
$$

Table 2 shows the 6-month physical cardiorespiratory training, which was composed of 72 training sessions of 60 minutes each, with 3 sessions per week. The training sessions consisted in low to moderate progressive walks between 2.2 MET and 3.6 MET in a horizontal plane, with a fluctuation of the maximum cardiovascular demand between $40 \%$ and $65 \%$ of $\mathrm{VO} 2 \mathrm{max}$, and with a maximum energy expenditure of $4.6 \mathrm{Kcal} / \mathrm{min}$.

\subsection{Statistical Analysis}

The statistical analysis was carried out using IBM-SPSS v.23. Means and standard deviations were obtained with descriptive statistics of central tendency and dispersion, respectively. We also obtained the confidence interval of the means at $95 \%$ as an indicator of reliability. Regarding the inferential statistics, the normality of the results was evaluated using the Kolmogorov-Smirnov test. The Levene statistic was obtained to determine the homoscedasticity between the groups. For the intragroup contrasts, the Student's $t$-test or Wilcoxon's test was carried out for related data, depending on the normality test. For the intergroup comparisons, the Student's $t$-test or Mann-Whitney $u$-test was conducted, depending on the normality and homoscedasticity test. The effect size was calculated using Cohen's d. It was considered that values below 0.2 indicated a small effect size, 0.5 represented a medium magnitude and 0.8 indicated a large effect size. 
Table 2. Cardiorespiratory training programme (walking).

\begin{tabular}{|c|c|c|c|c|c|c|c|c|c|c|c|c|c|c|c|c|c|c|c|c|c|c|c|c|}
\hline \multirow[b]{2}{*}{ Week } & \multicolumn{4}{|c|}{ Mesocycle 1} & \multicolumn{4}{|c|}{ Mesocycle 2} & \multicolumn{4}{|c|}{ Mesocycle 3} & \multicolumn{4}{|c|}{ Mesocycle 4} & \multicolumn{4}{|c|}{ Mesocycle 5} & \multicolumn{4}{|c|}{ Mesocycle 6} \\
\hline & 1 & 2 & 3 & 4 & 5 & 6 & 7 & 8 & 9 & 10 & 11 & 12 & 13 & 14 & 15 & 16 & 17 & 18 & 19 & 20 & 21 & 22 & 23 & 24 \\
\hline$\% \mathrm{VO}_{2 \max }$ & 40 & 45 & 40 & 45 & 50 & 45 & 50 & 45 & 50 & 55 & 50 & 55 & 50 & 55 & 55 & 60 & 50 & 60 & 55 & 60 & 65 & 55 & 60 & 65 \\
\hline Speed $(\mathrm{m} / \mathrm{min})$ & 56.2 & 67.6 & 56.2 & 67.6 & 79.0 & 67.6 & 79.6 & 67.6 & 79.0 & 90.4 & 79.0 & 90.4 & 79.0 & 90.4 & 90.4 & 102 & 79.9 & 102 & 90.4 & 102 & 112 & 90.4 & 102 & 112 \\
\hline Speed $(\mathrm{km} / \mathrm{h})$ & 3.3 & 4.0 & 3.3 & 4.0 & 4.7 & 4.0 & 3.3 & 4.0 & 4.7 & 5.4 & 4.7 & 5.4 & 4.7 & 5.4 & 5.4 & 6.1 & 4.7 & 6.1 & 5.4 & 6.1 & 6.3 & 5.4 & 6.1 & 6.3 \\
\hline METs & 2.2 & 2.5 & 2.2 & 2.5 & 2.7 & 2.5 & 2.7 & 2.5 & 2.7 & 3.0 & 2.7 & 3.0 & 2.7 & 3.0 & 3.0 & 3.3 & 2.7 & 3.3 & 3.0 & 3.3 & 3.6 & 3.0 & 3.3 & 3.6 \\
\hline $\mathrm{Kcal} / \mathrm{min}$ & 2.8 & 3.2 & 2.8 & 3.2 & 3.6 & 3.2 & 3.6 & 3.2 & 3.6 & 3.9 & 3.6 & 3.9 & 3.6 & 3.9 & 3.9 & 4.3 & 3.6 & 4.3 & 3.9 & 4.3 & 4.6 & 3.9 & 4.3 & 4.6 \\
\hline
\end{tabular}




\section{Results}

Table 3 shows the pre-post comparisons in EG for all the analysed variables. As can be observed, there was a statistically significant improvement in all physiological variables. Thus, while VO2max increased (Pre-test: 19.2; Post-test: 20.3; $p<0.001$ ) there was a significant decrease in plasma Hb1Ac concentration (Pre-test: 8.1; Post-test: 7.7; $p<0.001$ ) and a considerable decrease of BMI. The EG improved the cardiorespiratory fitness and the diabetic state. Regarding the cognitive state variables, the MMSE recorded a statistically significant increase (Pre-test: 23.04; Post-test: 23.96; $p<0.001$ ), with a large effect size. Lastly, all dimensions increased significantly, except calculation and language.

Table 3. Intragroup comparisons before (pre-test) and after (post-test) the intervention (mean, standard deviation and confidence interval).

\begin{tabular}{|c|c|c|c|c|c|c|c|}
\hline \multicolumn{8}{|c|}{ Experimental Group $(n=55)$} \\
\hline & \multicolumn{2}{|c|}{ Pre } & \multicolumn{2}{|c|}{ Post } & \multirow{2}{*}{$p$-Value } & \multirow{2}{*}{ Effect Size } & \multirow{2}{*}{ Magnitude } \\
\hline & Mean \pm SD & $95 \%(\mathrm{CI})$ & Mean \pm SD & $95 \%(\mathrm{CI})$ & & & \\
\hline HbA1c ${ }^{\text {(a) }}$ & $8.10 \pm 0.47$ & (7.97 to 8.2 ) & $7.73 \pm 0.55$ & (7.6 to 7.9$)$ & $<0.001$ & -0.66 & Medium \\
\hline BMI $^{(a)}$ & $25.54 \pm 2.17$ & (24.9 to 26.1 ) & $24.13 \pm 2.18$ & (23.5 to 24.7$)$ & $<0.001$ & -0.64 & Medium \\
\hline $\mathrm{VO}_{2 \max }{ }^{(a)}$ & $19.24 \pm 1.64$ & (18.8 to 19.7$)$ & $20.35 \pm 1.82$ & (19.8 to 20.8$)$ & $<0.001$ & 0.61 & Medium \\
\hline MMSE $^{(b)}$ & $23.04 \pm 0.69$ & (22.8 to 23.2 ) & $23.96 \pm 0.98$ & (23.7 to 24.2$)$ & $<0.001$ & 0.95 & Large \\
\hline Time Or. ${ }^{(b)}$ & $3.71 \pm 0.63$ & (3.54 to 3.88 ) & $4.38 \pm 0.59$ & (4.22 to 4.54$)$ & $<0.001$ & 1.10 & Large \\
\hline Spatial Or. ${ }^{(b)}$ & $3.76 \pm 0.58$ & (3.61 to 3.92$)$ & $4.20 \pm 0.59$ & (4.04 to 4.36$)$ & 0.001 & 0.75 & Medium \\
\hline Registration (b) & $2.02 \pm 0.62$ & (1.85 to 2.19$)$ & $2.36 \pm 0.59$ & (2.20 to 2.52$)$ & 0.001 & 0.57 & Medium \\
\hline Calculation $^{(b)}$ & $3.44 \pm 0.66$ & (3.26 to 3.61 ) & $3.53 \pm 0.72$ & (3.33 to 3.72 ) & 0.384 & 0.13 & Trivial \\
\hline Recall $^{(b)}$ & $2.35 \pm 0.67$ & (2.16 to 2.53 ) & $2.62 \pm 0.49$ & (2.49 to 2.75 ) & 0.009 & 0.46 & Medium \\
\hline Language $^{(b)}$ & $1.29 \pm 0.17$ & (1.24 to 1.34 ) & $1.32 \pm 0.13$ & (1.28 to 1.35$)$ & 0.168 & 0.18 & Trivial \\
\hline
\end{tabular}

* $p$-value: T test or Wilcoxon according to Normality. (a) Physiological variables and (b) Cognitive state variables; HbA1c: Glycosylated haemoglobin (\%); BMI: Body Mass Index $\left(\mathrm{kg} / \mathrm{m}^{2}\right) ; \mathrm{VO}_{2 \max }$ : Maximum Oxygen intake $(\mathrm{ml} / \mathrm{kg} / \mathrm{min}) ;$ MMSE: Mini-Mental State Examination (maximum score 30); MMSE dimensions: Time Orientation, Spatial Orientation, Registration, Calculation, Recall, Language (maximum score 5).

Table 4 shows the pre-post comparisons in CG. Unlike in EG, all variables obtained lower values at the end of the study. Thus, VO2max presented a significant decrease (Pre-test: 19.3; Post-test: 18.6; $p<0.001$ ). However, BMI (Pre-test: 25.7; Post-test: 18.6) and HbA1c (Pre-test: 8.1; Post-test: 8.4) registered an increase at the end of the intervention period, both statistically significant $(p<0.001)$. It is noted that the effect size was small or medium in physiological variables, while in MMSE total score (Pre-test: 23.3; Post-test: 22.5) the effect size was Large. All dimensions of cognitive status decreased significantly.

Table 4. Intragroup comparisons before (pre-test) and after (post-test) the intervention (mean, standard deviation and confidence interval).

\begin{tabular}{|c|c|c|c|c|c|c|c|}
\hline \multicolumn{8}{|c|}{ Control Group $(n=52)$} \\
\hline & \multicolumn{2}{|c|}{ Pre } & \multicolumn{2}{|c|}{ Post } & \multirow{2}{*}{$p$-Value } & \multirow{2}{*}{ Effect Size } & \multirow{2}{*}{ Magnitude } \\
\hline & Mean \pm SD & $95 \%(\mathrm{CI})$ & Mean \pm SD & $95 \%(\mathrm{CI})$ & & & \\
\hline HbA1c ${ }^{(a)}$ & $8.14 \pm 0.51$ & (8 to 8.3 ) & $8.45 \pm 0.56$ & (8.3 to 8.6$)$ & $<0.001$ & 0.56 & Medium \\
\hline BMI ${ }^{\text {(a) }}$ & $25.71 \pm 2.29$ & (25.1 to 26.3 ) & $26.6 \pm 2.44$ & (25.9 to 27.3 ) & $<0.001$ & 0.36 & Small \\
\hline $\mathrm{VO}_{2 \max }(\mathrm{a})$ & $19.35 \pm 1.53$ & (18.9 to 19.8$)$ & $18.6 \pm 1.27$ & (18.3 to 19$)$ & $<0.001$ & -0.55 & Medium \\
\hline $\operatorname{MMSE}^{(b)}$ & $23.33 \pm 0.65$ & (23.1 to 23.5 ) & $22.5 \pm 0.98$ & ( 22.2 to 22.7 ) & $<0.001$ & -0.86 & Large \\
\hline Time Or ${ }^{(b)}$ & $3.65 \pm 0.68$ & (3.46 to 3.84 ) & $3.31 \pm 0.64$ & (3.13 to 3.49$)$ & 0.002 & -0.52 & Medium \\
\hline Spatial Or ${ }^{(b)}$ & $3.81 \pm 0.56$ & (3.65 to 3.96 ) & $3.44 \pm 0.75$ & (3.23 to 3.65$)$ & 0.002 & -0.55 & Medium \\
\hline Registrat. (b) & $1.96 \pm 0.39$ & (1.85 to 2.07$)$ & $1.48 \pm 0.73$ & (1.28 to 1.68$)$ & $<0.001$ & -0.82 & Large \\
\hline Calculat. $^{(b)}$ & $3.35 \pm 0.76$ & (3.13 to 3.56$)$ & $2.67 \pm 0.78$ & (2.45 to 2.89$)$ & $<0.001$ & -0.87 & Large \\
\hline Recall $^{(b)}$ & $2.42 \pm 0.67$ & (2.24 to 2.61 ) & $2.04 \pm 0.74$ & (1.83 to 2.24$)$ & $<0.001$ & -0.55 & Medium \\
\hline Language $^{(b)}$ & $1.31 \pm 0.16$ & (1.27 to 1.35$)$ & $1.20 \pm 0.18$ & (1.15 to 1.25$)$ & $<0.001$ & -0.67 & Medium \\
\hline
\end{tabular}

* $p$-value: T test or Wilcoxon according to Normality. (a) Physiological variables and (b) Cognitive state variables; HbA1c: Glycosylated haemoglobin (\%); BMI: Body Mass Index $\left(\mathrm{kg} / \mathrm{m}^{2}\right) ; \mathrm{VO}_{2 \max }$ : Maximum Oxygen intake $(\mathrm{ml} / \mathrm{kg} / \mathrm{min}) ;$ MMSE: Mini-Mental State Examination (maximum score 30); MMSE dimensions: Time Orientation, Spatial Orientation, Registration, Calculation, Recall, Language (maximum score 5).

Table 5 presents the changes after the intervention (Post-test-Pre-test), and the comparisons between the two groups studied. The results clearly show that there was a totally different response in the group of women who carried out the exercise programme (EG) with respect to the group of 
women who only did their activities of daily living (CG). All the analysed variables showed statistically significant differences $(\mathrm{P}<0.001)$ with a magnitude effect size of large. The largest differences between groups were found in $\mathrm{HbA1c}$ and BMI with an effect size value of 2.2 and 1.8, respectively.

Table 5. Changes after the intervention. Between-group comparisons (mean, standard deviation and confidence interval).

\begin{tabular}{|c|c|c|c|c|c|c|c|}
\hline & \multicolumn{2}{|c|}{ Change Exp. Group $(n=55)$} & \multicolumn{2}{|c|}{ Change Control Group $(n=52)$} & \multirow{2}{*}{$p$-Value } & \multirow{2}{*}{ Effect Size } & \multirow{2}{*}{ Magnitude } \\
\hline & Mean \pm SD & $95 \%(\mathrm{CI})$ & Mean \pm SD & $95 \%(\mathrm{CI})$ & & & \\
\hline HbA1c ${ }^{(a)}$ & $-0.36 \pm 0.31$ & $(-0.45$ to 0.28$)$ & $0.31 \pm 0.30$ & $(0.23$ to 0.39$)$ & $<0.001$ & 2.20 & Large \\
\hline BMI $^{(a)}$ & $-1.41 \pm 1.63$ & $(-1.85$ to -0.96$)$ & $0.88 \pm 0.64$ & (0.70 to 1.06$)$ & $<0.001$ & 1.82 & Large \\
\hline $\mathrm{VO}_{2 \max }{ }^{(a)}$ & $1.11 \pm 1.20$ & $(0.79$ to 1.43$)$ & $-0.69 \pm 1.31$ & $(-1.06$ to -0.33$)$ & $<0.001$ & -1.44 & Large \\
\hline MMSE $^{\text {(b) }}$ & $0.93 \pm 1.1$ & (0.63 to 1.23$)$ & $-0.85 \pm 1.04$ & $(-1.13$ to -0.56$)$ & $<0.001$ & -1.66 & Large \\
\hline Time Or ${ }^{(b)}$ & $0.67 \pm 0.79$ & $(0.46$ to 0.89$)$ & $-0.35 \pm 0.74$ & $(-0.55$ to -0.14$)$ & $<0.001$ & -1.33 & Large \\
\hline Spatial Or ${ }^{(b)}$ & $0.44 \pm 0.83$ & (0.21 to 0.66$)$ & $-0.37 \pm 0.77$ & $(-0.58$ to -0.15$)$ & $<0.001$ & -1.00 & Large \\
\hline Registrat. (b) & $0.35 \pm 0.70$ & (0.16 to 0.53$)$ & $-0.48 \pm 0.61$ & $(-0.65$ to -0.31$)$ & $<0.001$ & -1.26 & Large \\
\hline Calculat. (b) & $0.09 \pm 0.78$ & $(-0.12$ to 0.30$)$ & $-0.67 \pm 0.55$ & $(-0.83$ to -0.52$)$ & $<0.001$ & -1.13 & Large \\
\hline Recall $^{(b)}$ & $0.27 \pm 0.73$ & $(0.07$ to 0.47$)$ & $-0.38 \pm 0.66$ & $(-0.57$ to -0.20$)$ & $<0.001$ & -0.94 & Large \\
\hline Language $^{(b)}$ & $0.03 \pm 0.15$ & $(-0.01$ to 0.07$)$ & $-0.11 \pm 0.16$ & $(-0.15$ to -0.06$)$ & $<0.001$ & -0.88 & Large \\
\hline
\end{tabular}

* $p$-value: T test or U Mann-Whitney according to Normality and Homoscedasticity; (a) Physiological variables and (b) Cognitive State variables; HbA1c: Glycosylated haemoglobin (\%); BMI: Body Mass Index $\left(\mathrm{kg} / \mathrm{m}^{2}\right) ; \mathrm{VO}_{2 \max }$ : Maximum Oxygen intake (ml/kg/min); MMSE: Mini-Mental State Examination (maximum score 30); MMSE dimensions: Time Orientation, Spatial Orientation, Registration, Calculation, Recall, Language (maximum score 5).

Figure 2 shows the percentage change of the Post-test with respect to the Pre-test in the physiological variables and in the results of the MMSE, comparing the analysed groups. As can be observed, the response of the groups is totally different in all variables. Thereby, $\mathrm{HbA} 1 \mathrm{c}$ and BMI decreased in the EG $(-4.5 \%$ and $-5.4 \%$ respectively), while in the CG both increased (3.8\% and $3.4 \%$ respectively). Regarding cardiorespiratory fitness (VO2max), the response was better in the EG (5.9\% increase), than the CG (-3.3\%). As for MMSE, the EG improved the score after the intervention program $(4.1 \%)$, while the CG declined $(-3.6 \%)$. All comparisons between groups showed statistically significant differences.

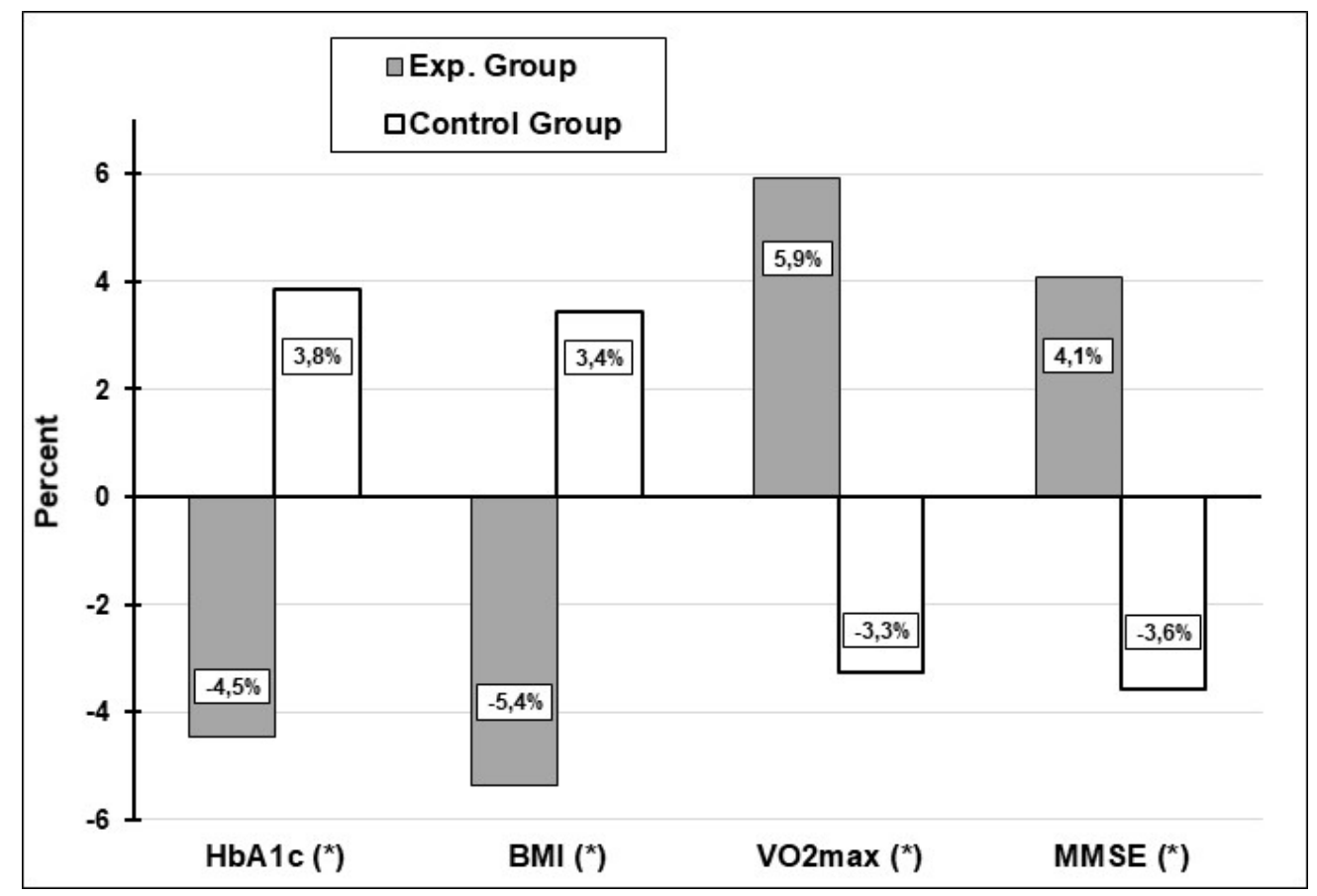

Figure 2. Between-group change percent comparisons; HbA1c: Glycosylated haemoglobin; BMI: Body Mass Index; VO2max: Maximum Oxygen intake MMSE: Mini-Mental State Examination; $\left({ }^{*}\right)$ Significant differences T Student test or U Mann-Whitney Test 
Figure 3 compares the percentage change of the cognitive state variables. The results are similar to those in Figure 2, that is, they are largely better in the EG than in the CG. While the EG improved all scores on all dimensions, the GC showed worse results on all dimensions at the end of the 6 months of intervention. The most important differences were recorded in registration (EG: $27 \%$ vs. CG: $-26 \%$ ) and recall (EG: 24\% vs. CG: $-15 \%$ ). The smallest differences were found in language (EG: $3 \%$ vs. CG: $-8 \%$ ). All dimensions showed statistically significant differences in between-group comparisons.

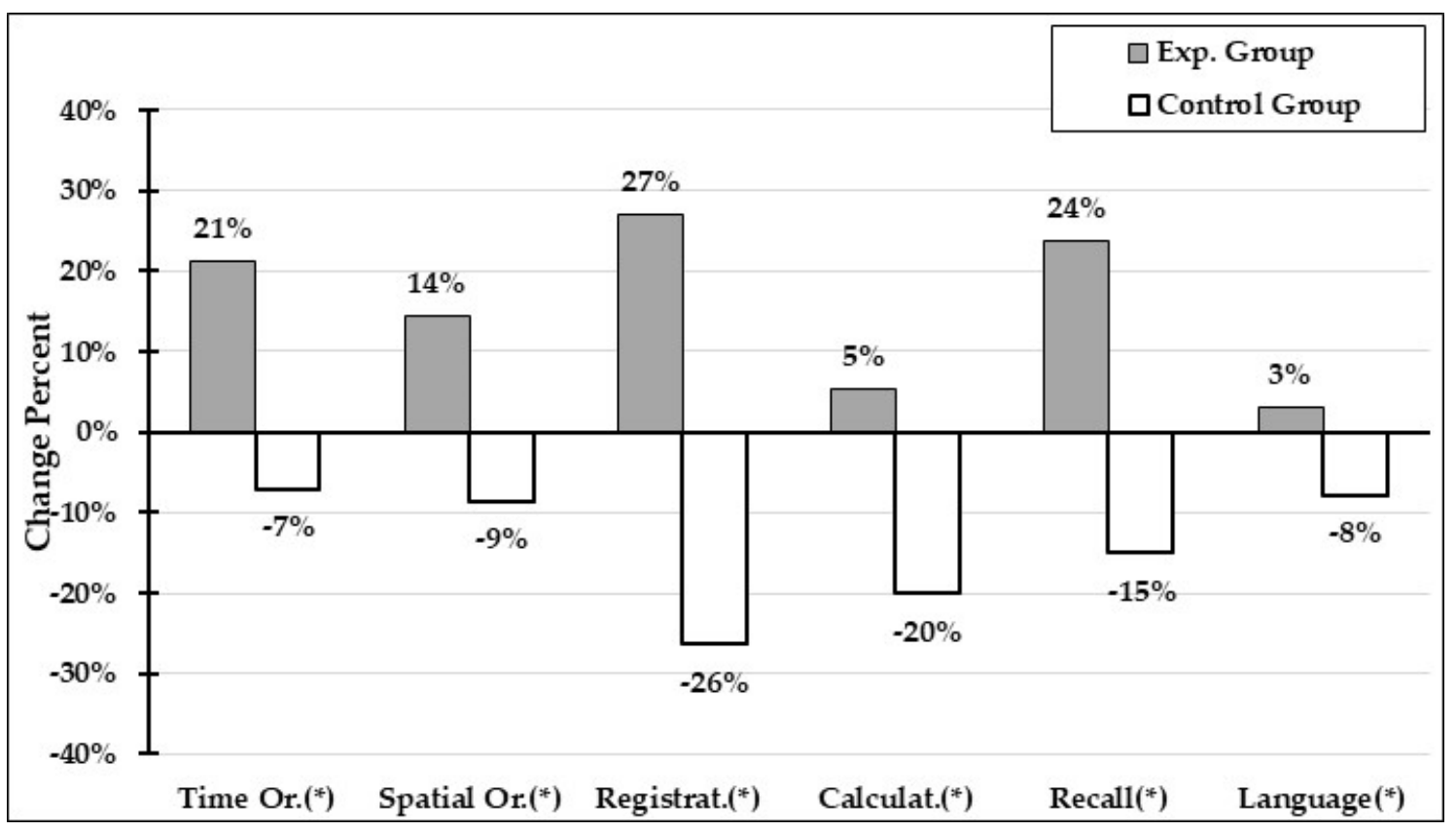

Figure 3. Between-group percentage change comparisons (MMSE dimensions); MMSE Dimensions: Time Orientation, Spatial Orientation, Registration, Calculation, Recall, Language (maximum score 5); ${ }^{*}$ ) Significant differences T Student test or U Mann-Whitney Test.

\section{Discussion}

The aim of this study was to verify whether aerobic physical exercise improves the levels of glycosylated haemoglobin and cognitive functioning in older women diagnosed with type 2 diabetes mellitus. To this end, the maximal aerobic power and BMI were evaluated as indicators of the degree of response to aerobic stimuli. Two groups of women diagnosed with type 2 diabetes were compared, with one of these groups conducting a 24-week cardiorespiratory training programme based on walking, whereas the other group maintained their usual activities of daily living.

\subsection{Cardiorespiratory Fitness}

The first consequence that can be attributed to the practice of physical activity is the significant improvement of VO2max in the experimental group (Table 3), whereas the control group showed a decrease in cardiorespiratory fitness (Table 4). These results are in line with those of numerous studies that demonstrate the importance of physical exercise in older adults [45-47], for instance in the improvement of aerobic power [48]; some studies even report that walking-based training programs improve the physical state in these populations [49]. On the contrary, a sedentary lifestyle in older adults with risk factors such as DM2 can have negative consequences on cardiovascular risk factors [50,51]. Corroborating the above mentioned in Table 5 and Figure 2, it is demonstrated that physical exercise is a determining factor of the different responses observed. These responses increased in the experimental group and decreased in the control group, and these differences were statistically significant between the two groups $(p<0.001)$, with a large effect size. 


\subsection{Body Mass Index}

Regarding BMI, there was a response practically identical to that observed in VO2max in the two groups. As is shown in Table 3 , the experimental group showed a significant decrease in BMI $(p<0.001)$ after completing the walk training, whereas the control group showed a statistically significant increase in this parameter after the 24-week period $(p<0.001)$. Most of the findings reported in the literature are in line with those obtained in this study, that is, the regular and systematic practice of exercise improves the BMI values in older populations [52]. Figure 2 presents the response obtained in the two groups, showing that a sedentary lifestyle has a negative impact on BMI [53].

\subsection{Glycosylated Haemoglobin}

The significant decrease observed in the experimental group after the 24-week walk training programme $(p<0.001$ and a medium effect size) is in line with the results of numerous recent studies that reported changes in HbA1c in older adults with DM2. For example, a recent study carried out with only 22 women with DM2 obtained a decrease of almost $1 \%$ of the levels of $\mathrm{HbA} 1 \mathrm{c}$ in the group subjected to the training programme [54], although the authors applied a Pilates program. However, exercise programs based on aerobic training in older women with DM2 have shown improvements in $\mathrm{HbA1c}$ levels [55]. A different study did not find a correlation between low-intensity physical exercise and improvements in HbA1c levels [56], although it was not an intervention study, as it evaluated physical activity via a telephone survey. Numerous studies demonstrate that the regular and systematic practice of physical exercise improves insulin resistance and $\mathrm{HbA1c}$ levels, even with low-intensity training programs [57-60], showing further efficiency with hypoglycaemic treatments [61]. These findings are in agree with the substantial difference in the response between the experimental group and the control group in HbA1c levels obtained in the present study (Figure 2). The lack of physical activity and a sedentary lifestyle lead to harmful responses related to insulin resistance and prediabetes indicators [62].

\subsection{Cognitive State}

Tables 3 and 4 show that the two groups began with mild cognitive deterioration. However, after the intervention period, the EG improved its MMSE score significantly $(p<0.001)$, almost reaching 24 points, with a large effect size. It has recently been reported that a multi-component physical exercise program did not improve cognitive function in participants with type 2 diabetes, perhaps because of the characteristics of the exercises program and the methodology design [63]. However, our results agree with several recent studies that reported improvements in cognitive deterioration in older women who carried out an aerobic exercise programme [64-67]. On the other hand, the CG showed a worse cognitive state after the 24-week study period, with a significant decrease in MMSE score $(p<0.001)$. This totally different behaviour between groups observed in cognitive deterioration (Figures 2 and 3 ) is corroborated with the statistically significant differences between the two groups shown by the data presented in Table 5 .

It has been demonstrated that DM is a pathology that enhances cognitive deterioration in older people $[18,20]$. The results obtained in the control group, who did not carry out any physical activity other than their usual activities of daily living (Figure 3 and Table 3), confirm this increase of cognitive deterioration in all the dimensions evaluated in the MMSE. This cognitive deterioration has been described in older adults with DM and mild cognitive impairment (MCI) [17], also affecting executive functions [21]. On the other hand, the experimental group showed a statistically significant improvement in all the dimensions of the MMSE, except in calculation and language (Table 3); however, when compared to the control group, significant differences were found between the two groups in the five dimensions and the opposite behaviour of these variables in the two groups (Table 5 and Figure 3). Although some authors have reported that the effect of exercise does not improve the cognitive level in all dimensions $[63,68]$, the scientific literature shows a large amount of recent evidence 
on the improvement of the cognitive state in older adults after carrying out different types of physical exercise programs [69-71]. Thus, specifically older adults with type 2 diabetes, undergoing structured physical training, have shown improvements in aspects of cognitive function such as concentration and attention [72]. In any case, robust, long-term, large-scale randomized controlled trials are required to determine whether exercise improves cognition in this group of population (elderly people with type 2 diabetes) [28,73].

\section{Conclusions}

The results obtained in this study demonstrate that a low-moderate intensity aerobic exercise programme reduces the plasma levels $\mathrm{HbA1c}$ in older women with type 2 diabetes mellitus. Similarly, the group of diabetic women who carried out the aerobic training programme significantly improved their cognitive functioning valued through the MMSE. Moreover, the active group showed an important improvement of their cardiorespiratory fitness and body mass index.

Author Contributions: All authors have read and agree to the published version of the manuscript. Conceptualization, J.A.G.-J. and E.M.-S.; methodology, A.C.-R. and E.M.-S.; software, W.O.-O.; validation, W.O.-O., and A.C.-R.; formal analysis, J.A.G.-J.; investigation, J.A.G.-J and E.M.-S.; resources, W.O.-O.; data curation, A.C.-R. writing—original draft preparation, E.M.-S. and J.A.G.-J.; writing—review and editing, W.O.-O. and A.C.-R.; visualization, J.A.C.-R.; supervision, J.A.G.-J.; project administration, W.O.-O. and E.M.-S.

Funding: This research received no external funding.

Acknowledgments: The authors wish to thank the participants in the study.

Conflicts of Interest: The authors declare no conflict of interest.

\section{References}

1. Naghavi, M.; Abajobir, A.A.; Abbafati, C.; Abbas, K.M.; Abd-Allah, F.; Abera, S.F.; Aboyans, V.; Adetokunboh, O.; Afshin, A.; Agrawal, A.; et al. Global, regional, and national age-sex specific mortality for 264 causes of death, 1980-2016: A systematic analysis for the Global Burden of Disease Study 2016. Lancet 2017, 390, 1151-1210. [CrossRef]

2. Roth, G.A.; Abate, D.; Abate, K.H.; Abay, S.M.; Abbafati, C.; Abbasi, N.; Abbastabar, H.; Abd-Allah, F.; Abdela, J.; Abdelalim, A.J.T.L. Global, regional, and national age-sex-specific mortality for 282 causes of death in 195 countries and territories, 1980-2017: A systematic analysis for the Global Burden of Disease Study 2017. Lancet 2018, 392, 1736-1788. [CrossRef]

3. Casals, C.; Casals Sanchez, J.L.; Suarez Cadenas, E.; Aguilar-Trujillo, M.P.; Estebanez Carvajal, F.M.; Vazquez-Sanchez, M.A. Frailty in older adults with type 2 diabetes mellitus and its relation with glucemic control, lipid profile, blood pressure, balance, disability grade and nutritional status. Nutr. Hosp. 2018, 35, 820-826. [CrossRef] [PubMed]

4. Salcedo Rocha, A.L.; Garcia de Alba, J.E.; de la Rosa Hernandez, S. Chronic pathology, frailty, and functionality in older adults from Guadalajara. Mexico. Aten. Primaria 2018, 50, 511-513. [CrossRef]

5. Chao, C.-T.; Wang, J.; Chien, K.-L.; COGENT. Both pre-frailty and frailty increase healthcare utilization and adverse health outcomes in patients with type 2 diabetes mellitus. Cardiovasc. Diabetol. 2018, 17, 130. [CrossRef]

6. Strain, W.D.; Hope, S.V.; Green, A.; Kar, P.; Valabhji, J.; Sinclair, A.J. Type 2 diabetes mellitus in older people: A brief statement of key principles of modern day management including the assessment of frailty. A national collaborative stakeholder initiative. Diabet. Med. 2018, 35, 838-845. [CrossRef]

7. Simpson, F.R.; Pajewski, N.M.; Nicklas, B.; Kritchevsky, S.; Bertoni, A.; Ingram, F.; Ojeranti, D.; Espeland, M.A. Impact of multidomain lifestyle intervention on frailty through the lens of deficit accumulation in adults with type 2 diabetes mellitus. J. Gerontol. A Biol. Sci. Med. Sci. 2019, 130, 1-7. [CrossRef]

8. Thein, F.S.; Li, Y.; Nyunt, M.S.Z.; Gao, Q.; Wee, S.L.; Ng, T.P. Physical frailty and cognitive impairment is associated with diabetes and adversely impact functional status and mortality. Postgrad. Med. 2018, 130, 561-567. [CrossRef] 
9. Meneilly, G.S.; Berard, L.D.; Cheng, A.Y.Y.; Lin, P.J.; MacCallum, L.; Tsuyuki, R.T.; Yale, J.-F.; Nasseri, N.; Richard, J.-F.; Goldin, L.; et al. Insights into the current management of older adults with type 2 diabetes in the ontario primary care setting. Can. J. Diabetes 2018, 42, 23-30. [CrossRef]

10. Tong, A.; Wang, X.; Li, F.; Xu, F.; Li, Q.; Zhang, F. Risk of depressive symptoms associated with impaired glucose metabolism, newly diagnosed diabetes, and previously diagnosed diabetes: A meta-analysis of prospective cohort studies. Acta Diabetol. 2016, 53, 589-598. [CrossRef]

11. Valenzuela, M.J.; Münzenmayer, B.; Osorio, T.; Arancibia, M.; Madrid, E. Sintomatologia depresiva y control metabólico en pacientes ambulatorios portadores de diabetes mellitus tipo 2. Rev. Med. Chil. 2018, 146, 1415-1421. [CrossRef] [PubMed]

12. Degmecic, D.; Bacun, T.; Kovac, V.; Mioc, J.; Horvat, J.; Vcev, A. Depression, anxiety and cognitive dysfunction in patients with type 2 diabetes mellitus-a study of adult patients with type 2 diabetes mellitus in Osijek, Croatia. Coll. Antropol. 2014, 38, 711-716. [PubMed]

13. Kotsani, M.; Chatziadamidou, T.; Economides, D.; Benetos, A. Higher prevalence and earlier appearance of geriatric phenotypes in old adults with type 2 diabetes mellitus. Diabetes Res. Clin. Pract. 2018, 135, $206-217$. [CrossRef] [PubMed]

14. Nogueira Costa, L.D.L.; Medeiros Verzaro, P.; Lopes Ericeira, V.V.; de Lima Sardinha, A.H. Cognitive deficit in older women with Type 2 Diabetes Mellitus. J. Nurs. UFPE 2016, 10, 2818-2824. [CrossRef]

15. Bangen, K.J.; Werhane, M.L.; Weigand, A.J.; Edmonds, E.C.; Delano-Wood, L.; Thomas, K.R.; Nation, D.A.; Evangelista, N.D.; Clark, A.L.; Liu, T.T.; et al. Reduced regional cerebral blood flow relates to poorer cognition in older adults with type 2 diabetes. Front. Aging Neurosci. 2018, 10, 270. [CrossRef]

16. Buss, S.S.; Padmanabhan, J.; Saxena, S.; Pascual-Leone, A.; Fried, P.J. Atrophy in distributed networks predicts cognition in alzheimer's disease and type 2 diabetes. J. Alzheimers Dis. 2018, 65, 1301-1312. [CrossRef]

17. Huang, X.; Wang, C.; Tian, S.; Huang, R.; Guo, D.; Zhang, H.; Shi, J.; Wang, S. Higher plasma level of nampt presaging memory dysfunction in chinese type 2 diabetes patients with mild cognitive impairment. J. Alzheimers Dis. 2019, 70, 303-314. [CrossRef]

18. Zheng, F.; Yan, L.; Yang, Z.; Zhong, B.; Xie, W. HbA1c, diabetes and cognitive decline: The English Longitudinal Study of Ageing. Diabetologia 2018, 61, 839-848. [CrossRef]

19. West, R.K.; Ravona-Springer, R.; Schmeidler, J.; Leroith, D.; Koifman, K.; Guerrero-Berroa, E.; Preiss, R.; Hoffman, H.; Silverman, J.M.; Heymann, A.; et al. The association of duration of type 2 diabetes with cognitive performance is modulated by long-term glycemic control. Am. J. Geriatr. Psychiatry 2014, 22, 1055-1059. [CrossRef]

20. Wium-Andersen, I.K.; Rungby, J.; Jørgensen, M.B.; Sandbæk, A.; Osler, M.; Wium-Andersen, M.K. Risk of dementia and cognitive dysfunction in individuals with diabetes or elevated blood glucose. Epidemiol. Psychiatr. Sci. 2020, 29, e43. [CrossRef]

21. Pappas, C.; Small, B.J.; Andel, R.; Laczo, J.; Parizkova, M.; Ondrej, L.; Hort, J. Blood glucose levels may exacerbate executive function deficits in older adults with cognitive impairment. J. Alzheimers Dis. 2019, 67, 81-89. [CrossRef] [PubMed]

22. Duarte, S.; Hoang, T.; Ewing, S.K.; Cawthon, P.M.; Cummings, S.; Stone, K.L.; Cauley, J.A.; Bauer, D.C.; Hillier, T.A.; Yaffe, K. Glycated peptide levels are associated with cognitive decline among nondiabetic older women. J. Gerontol. A Biol. Sci. Med. Sci. 2019, 74, 396-399. [CrossRef] [PubMed]

23. Mehta, B.K.; Singh, K.K.; Banerjee, S. Effect of exercise on type 2 diabetes-associated cognitive impairment in rats. Int. J. Neurosci. 2019, 129, 252-263. [CrossRef] [PubMed]

24. Macpherson, H.; Teo, W.-P.; Schneider, L.A.; Smith, A.E. A life-long approach to physical activity for brain health. Front. Aging Neurosci. 2017, 9, 147. [CrossRef] [PubMed]

25. Podolski, N.; Brixius, K.; Predel, H.G.; Brinkmann, C. Effects of regular physical activity on the cognitive performance of type 2 diabetic patients: A systematic review. Metab. Syndr. Relat. Disord. 2017, 15, 481-493. [CrossRef] [PubMed]

26. Espeland, M.A.; Lipska, K.; Miller, M.E.; Rushing, J.; Cohen, R.A.; Verghese, J.; McDermott, M.M.; King, A.C.; Strotmeyer, E.S.; Blair, S.N.; et al. Effects of physical activity intervention on physical and cognitive function in sedentary adults with and without diabetes. J. Gerontol. A Biol. Sci. Med. Sci. 2017, 72, 861-866. [CrossRef]

27. Vargas-Uricoechea, H.; Casas-Figueroa, L.Á. Epidemiología de la diabetes mellitus en Sudamérica: La experiencia de Colombia. Clínica Investig. Arterioscler. 2016, 28, 245-256. [CrossRef] 
28. Zhao, R.R.; O'Sullivan, A.J.; Fiatarone Singh, M.A. Exercise or physical activity and cognitive function in adults with type 2 diabetes, insulin resistance or impaired glucose tolerance: A systematic review. Eur. Rev. Aging Phys. Act. 2018, 15, 1. [CrossRef]

29. Dyer, A.H.; Briggs, R.; Mockler, D.; Gibney, J.; Kennelly, S.P. Non-pharmacological interventions for cognition in patients with Type 2 diabetes mellitus: A systematic review. QJM 2020, 113, 155-161. [CrossRef]

30. WMA. World Medical Association declaration of helsinki: Ethical principles for medical research involving human subjects. JAMA 2013, 310, 2191-2194. [CrossRef]

31. Folstein, M.F.; Folstein, S.E.; McHugh, P.R. "Mini-mental state”: A practical method for grading the cognitive state of patients for the clinician. J. Psychiatr. Res. 1975, 12, 189-198. [CrossRef]

32. Quiroga, L.P.; Albala, B.C.; Klaasen, P.G. Validación de un test de tamizaje para el diagnóstico de demencia asociada a edad, en Chile. Rev. Med. Chil. 2004, 132, 467-478. [CrossRef] [PubMed]

33. Llamas-Velasco, S.; Llorente-Ayuso, L.; Contador, I.; Bermejo-Pareja, F. Spanish versions of the Minimental State Examination (MMSE). Questions for their use in clinical practice. Rev. Neurol. 2015, 61, 363-371. [PubMed]

34. Muñoz Silva, C.A.; Rojas Orellana, P.A.; Marzuca-Nassr, G.N. Criterios de valoración geriátrica integral en adultos mayores con dependencia moderada y severa en Centros de Atención Primaria en Chile. Rev. Med. Chil. 2015, 143, 612-618. [CrossRef]

35. Laskin, J.J.; Bundy, S.; Marron, H.; Moore, H.; Swanson, M.; Blair, M.; Humphrey, R. Using a treadmill for the 6-minute walk test-Reliability and validity. J. Cardiopulm. Rehabil. Prev. 2007, 27, 407-410. [CrossRef]

36. Salci, Y.; Karanfil, E.; Balkan, A.F.; Kutukcu, E.C.; Ceren, A.N.; Ayvat, F.; Bekircan-Kurt, C.E.; Armutlu, K. Functional exercise capacity evaluated by timed walk tests in myasthenia gravis. Muscle Nerve 2019, 59, 208-212. [CrossRef]

37. Sperandio, E.F.; Arantes, R.L.; Matheus, A.C.; Silva, R.P.; Lauria, V.T.; Romiti, M.; Gagliardi, A.R.T.; Dourado, V.Z. Intensity and physiological responses to the 6-minute walk test in middle-aged and older adults: A comparison with cardiopulmonary exercise testing. Braz. J. Med. Biol. Res. 2015, 48, 349-353. [CrossRef]

38. Racodon, M.; Porrovecchio, A.; Pezé, T. Use of the 6-minute walk test to assess the pursuit of physical activity after cardiac rehabilitation. Rech. Soins Infirm. 2019, 137, 18-25. [CrossRef]

39. Giannitsi, S.; Bougiakli, M.; Bechlioulis, A.; Kotsia, A.; Michalis, L.K.; Naka, K.K. 6-minute walking test: A useful tool in the management of heart failure patients. Ther. Adv. Cardiovasc. Dis. 2019, 13, 1-10. [CrossRef]

40. Sakai, Y.; Yamamoto, S.; Hoshina, M.; Kawachi, S.; Ichiyama, T.; Hanaoka, M. Using SpO2 recovery index after a 6-minute walk test to predict respiratory-related events in hospitalized patients with interstitial pneumonia. Sci. Rep. 2019, 9, 15226. [CrossRef]

41. Lee, M.C. Validity of the 6-minute walk test and step test for evaluation of cardio respiratory fitness in patients with type 2 diabetes mellitus. J. Exerc. Nutr. Biochem. 2018, 22, 49-55. [CrossRef] [PubMed]

42. Ramírez Meléndez, A.; Arias Vázquez, P.I.; Lucatero Lecona, I.; Luna Garza, R. Correlation between the six-minute walk test and maximal exercise test in patients with type ii diabetes mellitus. Rehabilitacion 2019, 53, 2-7. [CrossRef] [PubMed]

43. Chan, W.L.S.; Pin, T.W. Reliability, validity and minimal detectable change of 2-minute walk test, 6-minute walk test and 10-meter walk test in frail older adults with dementia. Exp. Gerontol. 2019, 115, 9-18. [CrossRef]

44. Peralta-Brenes, M.; Briceno-Torres, J.M.; Chacon-Araya, Y.; Moncada-Jimenez, J.; Salazar-Villanea, M.; Johnson, D.K.; Campos-Salazar, C. Prediction o peak aerobic power among costa rican older adults. J. Clin. Diagn. Res. 2018, 12, CC1-CC4. [CrossRef]

45. Langhammer, B.; Bergland, A.; Rydwik, E. The importance of physical activity exercise among older people. BioMed Res. Int. 2018, 2018, 7856823. [CrossRef] [PubMed]

46. Outayanik, B.; Carvalho, J.; Seabra, A.; Rosenberg, E.; Krabuanrat, C.; Chalermputipong, S.; Suwankan, S.; Sirisopon, N.; Rachrujithong, P.; Thanak, W.; et al. Effects of a physical activity intervention program on nutritional status and health-related physical fitness in thai older adults: Pilot study. Asian J. Sports Med. 2017, 8, e37508. [CrossRef]

47. Viken, H.; Aspvik, N.P.; Ingebrigtsen, J.E.; Zisko, N.; Wisløff, U.; Stensvold, D. Correlates of objectively measured physical activity among norwegian older adults: The generation 100 study. J. Aging Phys. Act. 2016, 24, 369-375. [CrossRef] 
48. Pollock, R.D.; Duggal, N.A.; Lazarus, N.R.; Lord, J.M.; Harridge, S.D.R. Cardiorespiratory fitness not sedentary time or physical activity is associated with cardiometabolic risk in active older adults. Scand. J. Med. Sci. Sports 2018, 28, 1653-1660. [CrossRef]

49. LaRoche, D.P.; Melanson, E.L.; Baumgartner, M.P.; Bozzuto, B.M.; Libby, V.M.; Marshall, B.N. Physiological determinants of walking effort in older adults: Should they be targets for physical activity intervention? Geroscience 2018, 40, 305-315. [CrossRef]

50. Halloway, S.; Wilbur, J.; Schoeny, M.E.; Semanik, P.A.; Marquez, D.X. Combined effects of sedentary behavior and moderate-to-vigorous physical activity on cardiovascular health in older, community-dwelling Latinos. J. Aging Phys. Act. 2016, 24, 296-304. [CrossRef]

51. Bowden Davies, K.A.; Pickles, S.; Sprung, V.S.; Kemp, G.J.; Alam, U.; Moore, D.R.; Tahrani, A.A.; Cuthbertson, D.J. Reduced physical activity in young and older adults: Metabolic and musculoskeletal implications. Ther. Adv. Endocrinol. Metab. 2019, 10. [CrossRef]

52. Elhakeem, A.; Hannam, K.; Deere, K.C.; Hartley, A.; Clark, E.M.; Moss, C.; Edwards, M.H.; Dennison, E.; Gaysin, T.; Kuh, D.; et al. Physical activity producing low, but not medium or higher, vertical impacts is inversely related to BMI in older adults: Findings from a multicohort study. J. Gerontol. A Biol. Sci. Med. Sci. 2018, 73, 643-651. [CrossRef]

53. Stewart-Knox, B.; Duffy, E.M.; Bunting, B.; Parr, H.; Vas De Almeida, M.D.; Gibney, M. Associations between obesity (BMI and waist circumference) and socio-demographic factors, physical activity, dietary habits, life events, resilience, mood, perceived stress and hopelessness in healthy older Europeans. BMC Public Health 2012, 12. [CrossRef]

54. Melo, K.C.B.; Araújo, F.S.; Cordeiro Júnior, C.C.M.; de Andrade, K.T.P.; Moreira, S.R. Pilates method training: Functional and blood glucose responses of older women with type 2 diabetes. J. Strength Cond. Res. 2020, 34, 1001-1007. [CrossRef] [PubMed]

55. Jiang, Y.; Tan, S.; Wang, Z.; Guo, Z.; Li, Q.; Wang, J. Aerobic exercise training at maximal fat oxidation intensity improves body composition, glycemic control, and physical capacity in older people with type 2 diabetes. J. Exerc. Sci. Fit. 2020, 18, 7-13. [CrossRef] [PubMed]

56. Li, Y.; White, K.; O'Shields, K.R.; McLain, A.C.; Merchant, A.T. Light-intensity physical activity and cardiometabolic risk among older adults with multiple chronic conditions. Am. J. Health Promot. 2019, 33, 507-515. [CrossRef] [PubMed]

57. Cai, H.; Li, G.; Jiang, S.; Yin, H.; Liu, P.; Chen, L. Effect of low-intensity, Kinect ${ }^{\mathrm{TM}}$-based Kaimai-style Qigong exercise in older adults with type 2 diabetes. J. Gerontol. Nurs. 2019, 45, 42-52. [CrossRef]

58. Mendoza-Núñez, V.M.; Arista-Ugalde, T.L.; Rosado-Pérez, J.; Ruiz-Ramos, M.; Santiago-Osorio, E. Hypoglycemic and antioxidant effect of Tai Chi exercise training in older adults with metabolic syndrome. Clin. Interv. Aging 2018, 13, 523-531. [CrossRef] [PubMed]

59. Mendes, R.; Sousa, N.; Reis, V.M.; Themudo-Barata, J.L. Implementing low-cost, community-based exercise programs for middle-aged and older patients with type 2 diabetes: What are the benefits for glycemic control and cardiovascular risk? Int. J. Environ. Res. Public Health 2017, 14. [CrossRef]

60. Ng, C.L.; Goh, S.Y.; Malhotra, R.; Østbye, T.; Tai, E.S. Minimal difference between aerobic and progressive resistance exercise on metabolic profile and fitness in older adults with diabetes mellitus: A randomised trial. J. Physiother. 2010, 56, 163-170. [CrossRef]

61. Baptista, L.C.; MacHado-Rodrigues, A.M.; Martins, R.A. Back to basics with active lifestyles: Exercise is more effective than metformin to reduce cardiovascular risk in older adults with type 2 diabetes. Biol. Sport 2018, 35, 363-372. [CrossRef]

62. Esain, I.; Rodriguez-Larrad, A.; Bidaurrazaga-Letona, I.; Gil, S.M. Exercise cessation in active older adults: Effects on inflammatory markers and adiponectin. Geriatr. Gerontol. Int. 2020, 20, 1-6. [CrossRef] [PubMed]

63. Leite, N.J.C.; Mendes, R.D.C.; Raimundo, A.M.M.; Pinho, C.; Viana, J.L.; Marmeleira, J.F.F. Impact of a supervised multicomponent physical exercise program on cognitive functions in patients with type 2 diabetes. Geriatr. Nurs. 2020. [CrossRef]

64. Molina-Sotomayor, E.; Orb, M.G.; de la Fuente, F.P.; Figueroa, G.C.; Sánchez-Oliver, A.J.; González-Jurado, J.A. Effects of cardiorespiratory exercise on cognition in older women exposed to air pollution. Int. J. Environ. Res. Public Health 2019, 16, 245. [CrossRef] 
65. Molina-Sotomayor, E.; Arreguín-Moreno, R.; Rodríguez-Rodríguez, F.; Pradas, F.; León, J.A.; González-Jurado, J.A. Effects of exercise on the cognition of older women treated with lovastatin. Biomedica 2018, 38, 496-506. [CrossRef] [PubMed]

66. Guimarães, A.V.; Barbosa, A.R.; Meneghini, V. Active videogame-based physical activity vs. Aerobic exercise and cognitive performance in older adults: A randomized controlled trial. J. Phys. Educ. Sport. 2018, 18, 203-209. [CrossRef]

67. Zheng, G.; Xia, R.; Zhou, W.; Tao, J.; Chen, L. Aerobic exercise ameliorates cognitive function in older adults with mild cognitive impairment: A systematic review and meta-analysis of randomised controlled trials. Br. J. Sports Med. 2016, 50, 1443-1450. [CrossRef] [PubMed]

68. Briken, S.; Gold, S.M.; Patra, S.; Vettorazzi, E.; Harbs, D.; Tallner, A.; Ketels, G.; Schulz, K.H.; Heesen, C. Effects of exercise on fitness and cognition in progressive MS: A randomized, controlled pilot trial. Mult. Scler. J. 2014, 20, 382-390. [CrossRef] [PubMed]

69. Haripriya, S.; Dhanesh Kumar, K.U.; Samuel, S.E.; Ajith, S. The effect of a multicomponent exercise program on cognitive function and functional ability in community dwelling older adults. Int. J. Res. Pharm. Sci. 2020, 11, 109-114. [CrossRef]

70. Sáez de Asteasu, M.L.; Martínez-Velilla, N.; Zambom-Ferraresi, F.; Casas-Herrero, Á.; Cadore, E.L.; Galbete, A.; Izquierdo, M. Assessing the impact of physical exercise on cognitive function in older medical patients during acute hospitalization: Secondary analysis of a randomized trial. PLoS Med. 2019, 16, e1002852. [CrossRef]

71. Chang, M.; Ramel, A.; Jonsson, P.V.; Thorsdottir, I.; Geirsdottir, O.G. The effect of cognitive function on mobility improvement among community-living older adults: A 12-week resistance exercise intervention study. Aging Neuropsych. Cogn. 2019, 27, 1-12. [CrossRef] [PubMed]

72. Teixeira, R.B.; Marins, J.C.B.; Amorim, P.R.S.; Teoldo, I.; Cupeiro, R.; Andrade, M.O.C.D.; Martins, Y.D.L.X.; Castilho, P.D.R.; Magalhães, D.D.; Palotás, A.; et al. Evaluating the effects of exercise on cognitive function in hypertensive and diabetic patients using the mental test and training system. World J. Biol. Psychiatry 2019, 20, 209-218. [CrossRef] [PubMed]

73. Callisaya, M.L.; Daly, R.M.; Sharman, J.E.; Bruce, D.; Davis, T.M.E.; Greenaway, T.; Nolan, M.; Beare, R.; Schultz, M.G.; Phan, T.; et al. Feasibility of a multi-modal exercise program on cognition in older adults with Type 2 diabetes-A pilot randomised controlled trial. BMC Geriatr. 2017, 17, 237. [CrossRef] [PubMed]

(C) 2020 by the authors. Licensee MDPI, Basel, Switzerland. This article is an open access article distributed under the terms and conditions of the Creative Commons Attribution (CC BY) license (http://creativecommons.org/licenses/by/4.0/). 